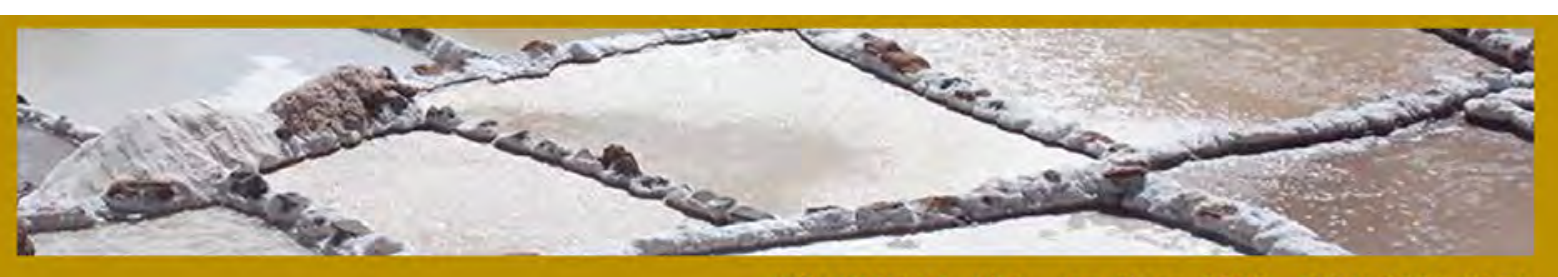

\title{
APROPRIAÇÕES DA LINGUAGEM FOTOGRÁFICA SOBRE “TRABALHO” POR ALUNOS DO ENSINO MÉDIO NAS AULAS
}

\author{
DE ARTE
}

\section{APPROPRIATIONS OF THE PHOTOGRAPHIC LANGUAGE ON \\ "WORK" BY STUDENTS OF MIDDLE SCHOOL IN THE LESSONS OF ART}

DOI: http://dx.doi.org/10.5965/1984317814012018007

Laudo Rodrigues Sobrinho - Universidade Metodista de Piracicaba

\begin{abstract}
RESUMO
Este artigo configura-se como síntese da tese defendida a pouco, onde estudei com alunos de uma Escola Estadual, no interior do estado de São Paulo, nas aulas de Arte, produziram fotografias e discutiram sobre elas. Escolhas teóricas e metodológicas de investigação estabeleceram-se em diálogo com minha formação e o contexto da pesquisa ocorreu em um município de economia, predominantemente, rural. $\mathrm{O}$ objetivo do trabalho foi estudar como a linguagem fotográfica podem favorecer as reflexões desses alunos do Ensino Médio, a problematizarem a realidade na qual estão inseridos. Partimos da questão: é possível que por meio da produção de fotografias e das discussões sobre elas que os alunos se apropriem de significações de sua realidade e conceituem o "trabalho" de forma diferenciada ao conceito dado pelo Currículo Oficial? A seleção de quatro imagens, com seus respectivos turnos dialógicos, compôs o material. A temática se verificou na medida em que as análises mostraram, da parte dos alunos, tanto a apropriação de regras formais de composição da fotografia quanto a possibilidade de significações do mundo em que vivem, a partir da relação com o professor/pesquisador. Essa pesquisa configurou-se como Participante e atende respectivamente a interesses da Educação e do ensino de Arte.
\end{abstract}

Palavras-chaves: Fotografia; Dialogia; Educação; Ensino de Arte; Ensino Médio.

\begin{abstract}
This article is a summary of the thesis that I defended in the near future, where I studied as students of a State School, in the interior of the State of São Paulo, in art classes, produced photographs and discussed them. Theoretical and methodological choices of research were established in dialogue with my training and the context of the research occurred in a predominantly rural economy municipality. The objective of the work was to study how the photographic language can favor the reflections of these high school students, to problematize the reality in which they are inserted. We start from the question: is it possible, through the production of photographs and the discussions about them, that the students take ownership of their reality and conceptualize the "work" differently from the concept given by the Official Curriculum? The selection of four images, with their respective dialogical shifts, composed the material. The thematic was verified to the extent that the analyzes showed, on the part of the students, both the appropriation of formal rules of composition of the photograph and the possibility of significations of the world in which they live, from the relation with the teacher / researcher. This research was configured as a Participant and serves respectively the interests of Education and Art education.
\end{abstract}

Keywords: Photography. Dialogy. Education. Art Education. High School. 


\section{INTRODUÇÃO}

Na maioria dos artigos por mim lidos, o autor inicia com a explanação de seus referenciais e a descrição de seus caminhos metodológicos. Na elaboração deste artigo, eu me distancio, a princípio, destas regras por entender que, ao estudar alguma coisa, esta deve ser estudada em movimento ou, melhor dizendo, que as relações e interações entre os sujeitos, suas condições concretas de vida, a dinâmica e o contexto social devam efetivamente ser considerados.

Permearão meu estudo não somente a fundamentação teórica a que me proponho, mas minhas condições de vida concreta, histórica e simbólica, que deverão estar relacionadas e contextualizadas com as apropriações fotográficas e dialógicas dos sujeitos desta pesquisa.

Acredito que essas apropriações sobre representações humanas, nesse momento, possam ser entendidas com as palavras de Buoro (1998. p. 20) quando afirma serem elas "essenciais ao desenvolvimento da consciência propiciando ao homem contato consigo mesmo e com o outro".

Estas experiências e vivências não aconteceram no vazio, mas no movimento de uma história pessoal - que é, deste modo, também memória de quem eu fui e de quem venho sendo. Recebia e recebo estímulos que me eram e são prazerosos por propiciarem novas formas de ver o mundo e nele poder me posicionar. Assim, intuitivamente, formam minhas apropriações e introspecções a partir do plano social, trazendo o que estava consolidado como conhecimento culturalmente construído pela humanidade para que em mim se transformasse em conhecimento pessoal.

Dentre estes fatos marcantes, destaco minha aproximação com a fotografia, que se deu de forma repentina e inesperada pois, aos 11 anos assumi a produção das fotografias da coluna de meu pai por seu fotógrafo ficar convalescente por um ano devido a um acidente automobilístico. Aos 16 anos efetivamente me profissionalizei.

Ao me formar professor de Arte em 1993, passo a incorporar essa como principal poética artística e comunicacional de minha prática. 


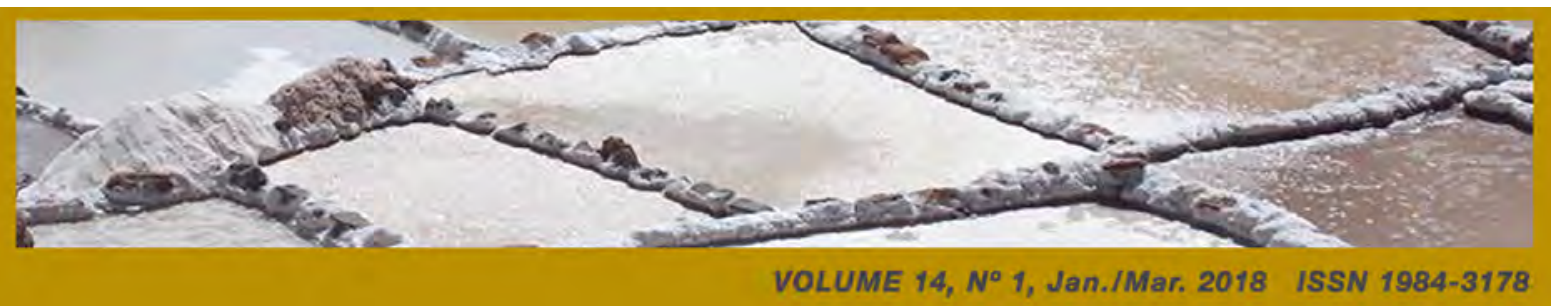

Em 2010, fui removido para a Escola Estadual "Pedro Bento Alves", em Arandu, no interior de São Paulo, na região de Avaré, no Sudoeste Paulista. Os sujeitos desta pesquisa foram meus alunos desde o sexto ano do Ensino Fundamental e no segundo ano do Ensino Médio iniciei os trabalhos com fotografia por este ser um conteúdo do Currículo Ofícial do Estado de São Paulo.

Pela primeira vez, aqueles alunos estavam tendo, de forma sistematizada, o ensino de fotografia, o que para eles significava descortinar uma gama de infinitas possibilidades. Kossoy (2002) nos ensina que este processo se dá devido:

A imagem fotográfica não é um simples registro físico-químico ou eletrônico do objeto fotografado: qualquer que seja o objeto da documentação não se pode esquecer que a fotografia é sempre uma representação a partir do real intermediada pelo fotógrafo que a produz segundo sua forma particular de compreensão daquele real, seu repertório, sua ideologia. A fotografia é, como já vimos reiteradas vezes, o resultado de um processo de criação/construção técnico, cultural e estético elaborado pelo fotógrafo. (KOSSOY, 2002. p. 52)

Não é que não havia fotografia na escola ou em suas vidas. Havia e muita. Tanto que a maioria dos alunos, antes de minha chegada a essa escola, já dispunham de câmeras ou aparelhos de telefonia celular, com câmeras acopladas, porém fotografavam de maneira laissez-faire, preocupados apenas com a extasia pelo fotografar.

Em 2014, aqueles alunos estavam matriculados no terceiro ano do Ensino Médio, tendo sido meus alunos em todos os anos antecedentes. Foi, então, que realizei a coleta de dados da pesquisa.

O grupo era composto de 33 alunos, sendo a maioria meus alunos desde meu início na escola. Assim, na convivência por sete anos, fomos formando vínculos. Eram discutidos nossos problemas e compartilhadas nossas alegrias. Efetivamente, havia forte interação entre professor e alunos.

Essa aproximação acabou sensibilizando o grupo, positivamente, em relação à Arte. Pintamos muito, esculpimos, fomos a algumas exposições em São Paulo e depois 


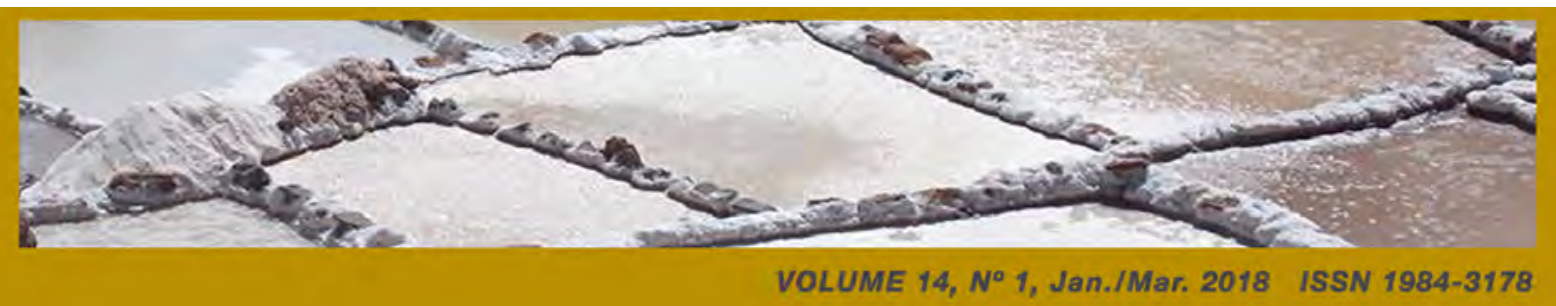

pintamos releituras em painéis de madeira para decorar todos os corredores da escola, sempre partindo do que foi visto na capital.

As duas aulas semanais sempre foram divididas sistematicamente entre uma aula destinada ao Caderno do Aluno (material didático apostilado fornecido pela Secretaria da Educação do Estado) e a outra dedicada à proposições da turma e do professor.

Somente no segundo ano do Ensino Médio é que iniciei os estudos em fotografia, por este ser um dos conteúdos do Currículo Oficial do Estado de São Paulo. Em especial, por opção da turma, a segunda aula da semana foi dedicada para que fotografassem.

As questões sobre a reflexão da realidade e as possíveis maneiras de transformála sempre permearam minhas ações como professor. E a fotografia esteve presente em todos os momentos, sobretudo atrelada à arte.

Isto posto, desenvolvi a Tese que este artigo sintetiza e, agora consolida esses escritos, tendo por objetivo estudar como a linguagem fotográfica e suas técnicas de produção podem favorecer as reflexões dos alunos do Ensino Médio, de uma escola pública, do interior de São Paulo, a problematizarem a realidade na qual estão inseridos.

Para tal, procurei responder a seguinte questão de investigação: como os alunos do Ensino Médio, participantes das aulas de Arte, pela mediação do professorpesquisador, apropriam-se da linguagem fotográfica e, ao produzirem suas fotos, refletem acerca da própria realidade?

Assim a principal intenção foi de estudar se é possível por meio da produção de fotografias e das discussões sobre elas que os alunos se apropriem de significações de sua realidade e conceituem o trabalho de forma diferenciada ao conceito dado pelo Currículo Oficial. Por este enfatizar os estudos como preparação para o mercado de trabalho.

Sempre assumi a concepção de trabalho como sendo qualquer atividade humana que transforme a natureza em bens de consumo ou em bens de serviço, portanto, 
qualquer empenho das pessoas na realização de tarefas, cotidianas ou não, configuro como trabalho.

\section{FUNDAMENTAÇÃO TEÓRICA}

Reconheço que a representação criada pelo aluno está vinculada às suas condições concretas de vida, segundo Deliberador (2013):

A fotografia representa a realidade por meio de um discurso, no qual os elementos de sua linguagem the empregam determinados sentidos. Saber interpretar tais significações e empregá-las para a construção de um discurso próprio sobre o real [...] (DELIBERADOR, 2013, p. 15)

Ferreira (2012a), ao falar das representações, nos diz "As representações visuais contribuem para dar sentido em constante interação conosco", mais adiante afirma "As imagens interpretam e produzem o mundo em termos visuais" (p.30). Portanto, a fotografia é resultante da intencionalidade do fotógrafo e da programação contida nos instrumentos.

Cada uma das fotografias de meus alunos foi elaborada a partir de suas concepções de mundo e na forma que eles se relacionam com os conhecimentos socialmente adquiridos. Embora, não podemos esquecer que durante todo o decorrer do segundo e terceiro ano do Ensino Médio como também em todo o decorrer da pesquisa de campo procurei subsidiar tecnicamente conhecimentos e reflexões sobre fotografia que garantissem as interpretações e construções coletivas sobre seu mundo real.

Fotografia é sempre representação (Duarte, 2000, Deliberador, 2013), e, muito embora represente um fragmento da realidade, dela se distancia uma vez que é carregada de interpretações pessoais, de cunho valorativo, de concepção ou preferência técnica. Sendo assim, é prenhe de apropriações subjetivas, não sendo inocente em sua intencionalidade, vem programada pelo fotógrafo e pelo instrumento. 
Sobre a tônica da representação, Ferreira (2012b), embora diga de forma diferente, ainda assim, antecipa as intenções do fotógrafo/autor:

Dessa forma, podemos considerar que toda fotografia é uma ficção que nos é apresentada como uma verdade; como verdadeira, o que importa não é essa mentira inevitável, mas como o fotógrafo a utiliza e com que propósito. (FERREIRA, 2012b, p. 19).

Segundo Rouillé (2009), quando nos fala sobre as seleções formais realizadas pelo fotógrafo autor, aponta que este não fotografa o real nem mesmo no real, todavia seu ato de fotografar se dá com o real. "A extensão excede às coisas e aos corpos, que jamais se inserem na imagem sem estarem ligados aos incorporais” (p. 202).

Ainda versando sobre o processo dialético entre fotografia, realidade e aos incorporais de Rouillé, encontro pensamento equivalente em Kossoy (2002) quando nos diz:

A fotografia tem uma realidade própria que não corresponde necessariamente à realidade que envolveu o assunto, objeto do registro, no contexto da vida passada. Trata-se da realidade do documento, da representação: uma segunda realidade, construída, codificada, sedutora em sua montagem, em sua estética, de forma alguma ingênua, inocente, mas que é, todavia, o elo material do tempo e espaço representado, pista decisiva para desvendarmos o passado. (KOSSOY, 2002. p. 22)

Deliberador (2013) reafirma os postulados de Rouillé e de Kossoy quando em seu trabalho, ao se apropriar de um período da história da fotografia, diz:

A fotografia já foi entendida como o "espelho da realidade", como se tomasse naturalmente as cenas do mundo natural. Todavia, entende-se que não é bem assim, que a fotografia é apenas um traço do real. (DELIBERADOR, 2013. p. 20 - grifos meus) 


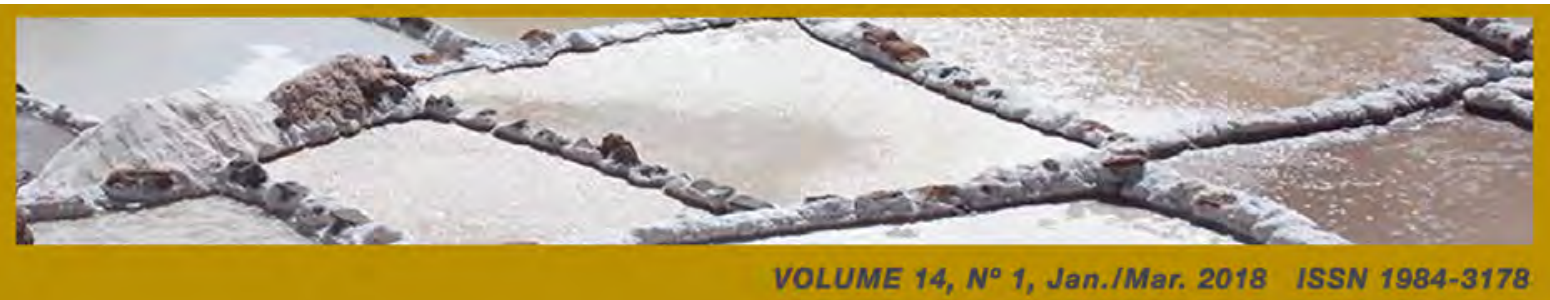

Sobre a ideia de sua aproximação com a realidade que as fotografias propiciam ao observador, embora divergente às proposições anteriores e evidentemente, construídas sobre outra base epistemológica, Sontag (2004) nos ensina: "as fotos modificam e ampliam nossas ideias [...]. Colecionar fotos é colecionar o mundo" (p.13).

O pensamento de Sontag (2004) sobre a ampliação das ideias oportuniza aos alunos possibilidades de compreenderem e se manifestarem sobre a realidade do documento (Kossoy, 2002), considerando de maneira mais elucidativa a intencionalidade do fotógrafo e como este representou a realidade que construiu.

Isto posto, a fotografia difere substancialmente daquilo que entendo por imitação, pois carrega em si a expressão de uma relação aberta/incompleta do sujeito com o mundo, sendo que o fotógrafo/autor, no momento do registro, antevê as possibilidades de interpretação do observador e a ele destina sua composição na tentativa de dirigir seu olhar. Segundo Nobre (2011. p.110) esse processo se dá em função da fotografia ser um signo e estar condicionada a uma linguagem específica e peculiar relacionada com a cultura de seu produtor.

Mesmo para um observador genérico, o fotógrafo/autor procura, à sua maneira, deixar explicitadas ao observador suas posições axiológicas, ideológicas e culturais, pois ainda segundo Sontag (2004) "a câmera é o braço ideal da consciência [...]" (p.14). Portanto, essa autora sinaliza a fotografia como um exercício na elaboração do pensamento.

Em sua orquestração da fotografia, ou melhor dizendo, na sua elaboração, perpassam os conceitos do fotógrafo/autor de história, de ética, de técnica, como também de seu cotidiano, 0portanto a orquestração se dá em função das condições concretas de vida social de seu autor. Ponto de vista este também compartilhado por Gonçalves (2009), que em suas palavras expressa:

A imagem depende dos símbolos e códigos circundantes e compartilhados no período em que foi produzido ou dentro do grupo ao qual pertence o autor. A construção da imagem é função das possibilidades de ver e compreender que pertencem à época na qual 
o sujeito que a realiza está inserido. (GONÇALVES, 2009, p. 236 grifo meu).

Sendo irrefutável a proposição de que a fotografia se constitui de códigos e símbolos compartilhados e a sua época, Nobre (2011) completa com pouco mais de propriedade. São suas palavras:

[...] estão contidas partes das informações culturais, captadas pelo seu autor, mas em um movimento hologramático podem representar o itinerário de pensamento de quem as capturou e do mundo das ideias da cultura dominante.

Dessa forma, a partir da fotografia, o ser humano chega a representar o seu mundo, o seu espaço e o outro no qual se espelha, enfim, o que apreende, e a partir da memória social do ser humano, um mundo repleto de representações e de aspectos simbólicos serão os elementos que configuram sua estruturação enquanto ser social, determinadas condutas, e diversificadas crenças. (NOBRE, 2011, p. 110)

Assim, considerando-se o visto há pouco, na fotografia está contida toda a interpretação da narrativa social sobre determinado aspecto, isto é, do que foi fotografado, fator determinado única e exclusivamente pelo fotógrafo, ainda que mediado pelos seus vínculos com a sociedade.

\section{MÉTODO}

Em passeios pela pequena Arandu, os alunos fotografaram pessoas, a paisagem urbana, detalhes como texturas de chão, parede e o que mais lhes satisfizessem. Ao retornar para a escola, um dos alunos ficava responsável em transferir as fotografias para uma pasta única. Na sequência, eu montava em power point todas as fotografias e em projeção fazia correções e elaborava sugestões para a aula seguinte.

Aos poucos, os alunos foram se soltando e sem melindre criticavam todas as fotos. Os resultados após as discussões passaram a originar fotos mais bem elaboradas 
e, assim, fotografar, discutir e (re)fotografar para novamente ser discutido passou a ser uma constante.

No ano seguinte, isto é, no terceiro ano do Ensino Médio, contexto deste estudo, os alunos optaram em continuar o trabalho com fotografia na aula em que permitia que optassem sobre o que seria feito.

Como combinado, dei sequência nas aulas específicas de fotografia, porém, neste ano, o tema a ser desenvolvido seria "o trabalho", aceitando qualquer forma de apropriação fotográfica que fizesse referência ao tema dado.

Dei aos alunos minha conceituação de trabalho como sendo aquela que se manifesta pela atuação laborativa do homem, ou seja, qualquer ação humana que vise a transformação da natureza em bens ou a execução de tarefas cotidianas se constitui como trabalho. Reconheço que essa conceituação é distante da conceituação do Currículo Oficial do Estado de São Paulo. Embora explicitamente no Currículo não haja contraposição ao meu conceito, ele enfatiza apenas a preparação para o mercado de trabalho.

Essa divergência entre conceitos será tensionada durante todo o decorrer deste trabalho, pois como pessoa, como profissional e, finalmente, como pesquisador, penso que não deva aceitar que se passe por todo um ciclo de estudos apenas para se ter o direito à entrada no mercado de trabalho.

Ainda sou uma das pessoas que acredita que a escola serve para ensinar e para preparar a pessoa para a vida. Assim, o direito à entrada ao mercado de trabalho é apenas um dos matizes possíveis.

Dos encontros realizados, apenas três deles foram gravados em vídeo. Nos demais encontros, realizamos gravação em áudio feita através de um computador portátil.

$\mathrm{Na}$ data marcada, 18 sujeitos entregaram os termos de consentimento. No universo de trinta e três alunos, quatro fotografias foram selecionadas, considerando as apropriações das regras formais ensinadas e a participação nas discussões sobre as fotos. 
As transcrições foram realizadas observando-se as expressões faciais, as entonações de voz, as pausas ou qualquer outro pormenor que indiciasse sentidos. Como apoio destes elementos nas gravações de áudio foi utilizado o caderno de campo. Nele anotei a última palavra dos sujeitos e os índices que reconheci como importantes.

Para que fosse garantido o direito de confidencialidade dos sujeitos seus nomes fictícios foram orientados a partir de nomes escolhidos pelos próprios alunos.

A partir da análise dos diálogos transcritos, elaborei três categorias que se destacaram numa primeira leitura. A partir dessa classificação, construí três discussões sobre o modo como os alunos se apropriaram das técnicas fotográficas e como refletiram sobre sua realidade.

\section{ANÁLISE FORMAL}

Anteriormente dei ao leitor uma síntese de minha constituição como sujeito, após trouxe à tona conceitos circundantes de fotografia que me apropriei, agora trago como um dos alunos se apropriou destes conceitos, das regras formais e o que delas falou.

Mas antes, cabe, aqui, trazer as palavras de Deliberador (2013) por sintetizar minha intenção. São suas palavras:

Para elaborar significados, além de contar com seu repertório cultural, político e social, é necessário que o fotógrafo domine e saiba explorar o vocabulário da linguagem fotográfica. Estes dois fatores lhe permitem imprimir sua intencionalidade de comunicação no ato fotográfico. (DELIBERADOR, 2013, p. 22).

Ainda na explicitação de minha intenção balizo-me nas palavras de Ostrower (1998) quando afirma que "na arte, a técnica sempre se torna uma questão de formas e conteúdos expressivos (p.168)”. Tais formas e conteúdos acabam por favorecer a 
compreensão da fotografia, seja pelo fotógrafo/autor na elaboração de sua composição ou ainda como observador, quando este fotógrafo se torna o outro. Mais adiante nos ensina que:

[...] numa imagem, qualquer linha funciona como se fosse uma seta. Ela diz: "olhe para mim, siga daqui para lá", e nós somos obrigados a olhar assim como o artista colocou, seguindo ao longo desta linha e na direção que ela indica. $\mathrm{O}$ mesmo ocorre com relacionamentos formais de cores, superfícies, volumes, contrastes e ritmos visuais. Eles sempre configuram situações espaciais - e nós as interpretamos espontaneamente. (OSTROWER, 1998, p.174 - grifos meus).

Para tal, os elementos formais em que trabalhei com os alunos, representados abaixo, proporciona a compreensão da composição.

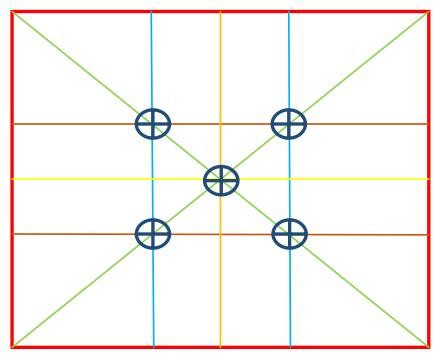

Eixo Vertical

Eixo Horizontal

Terços Verticais

Terços Horizontais

Diagonais

Pontos áureos

Figura 1-Diagrama das Linhas de Força - Elaboração do Autor 


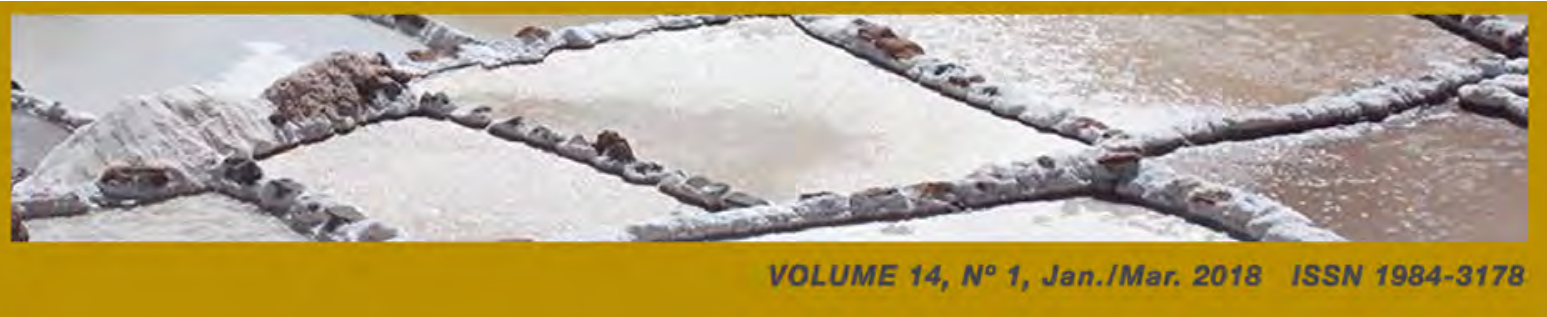

A primeira das fotografias discutidas com os alunos, foi de Eli, que a produziu em condições adversas criadas pela falta de energia elétrica em sua residência, fato que criou espanto e bastantes risos em todos. Essa foto se distinguiu de todas as outras pelo seu processo de criação e, principalmente, por transgredir a condição de luz favorável à fotografia, optando por uma condição onde utilizou filtro colorido para obter o resultado imaginado.

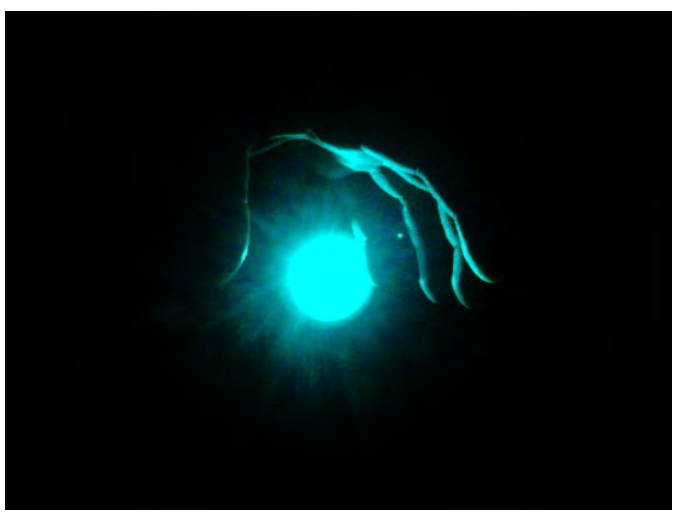

Figura 2 - Fotografia de Sujeito - Eli

Professor

Eli

Professor

Eli
Bom, essa é a foto da Eli... Eli, eu vejo que é uma mão e uma luz de um abajur. É isso?

Não, é a luz de uma lanterna... da lanterna do meu pai...

A luz de uma lanterna! Como é que você teve a ideia de fazer isso?

Ah... tinha acabado a luz lá em casa (ri da situação), eu estava no meu quarto, dai eu ia ler (todos riem, e essa aluna continua sua fala entre risos) [...] (parte inaudivel devido aos risos). Aí depois eu peguei meu celular e "tava" mexendo nele (parte inaudivel) aí pensei em fazer a foto. 


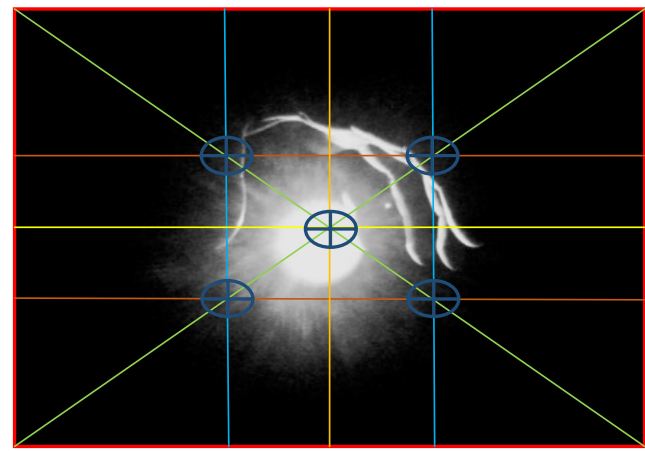

Figura 3- Diagrama das Linhas de Força sobre fotografia de Eli

\section{Eixo Vertical}

Este eixo, ao dividir a composição fotográfica, dá o sentido de simetria ao passar muito próximo ao centro do ponto de iluminação colocado sobre o centro geográfico da composição, a posição da mão dividida exatamente em sua metade e iluminada apenas em sua parte interior reforçam a simetria.

\section{Eixo Horizontal}

Se comportando como no eixo vertical, este eixo também corta o centro geográfico da fotografia onde está colocado o ponto de luz. A leve descentralização do ponto de luz em relação ao eixo se dá em decorrência de sua passagem pela primeira falange dos dedos que apontam para baixo.

\section{Terços Verticais}

Estão contidos no primeiro terço, a diminuta parte do polegar e a luminescência do ponto de luz. Já o segundo terço - central, concentra os elementos da composição, nele está contido, integralmente, o ponto de luz e quase a totalidade da mão. Como estes elementos se concentram neste terço não há possibilidade de transição temporal ou espacial, configura-se como um momento único atemporal. Contudo, isso faz com que o equilíbrio e simetria da composição sejam reforçados.

\section{Terços Horizontais}


O terço superior concentra apenas a parte superior da mão e um semicírculo pequeno de luminescência. Já o terço intermediário, além de concentrar a totalidade do ponto de luz ainda contém a maior porção da mão, isto é, os cinco dedos integralmente. Para o terço inferior apenas ficou representado a luminescência formada por semicírculo pouco maior que o representado no terço superior. A diferença dos dois semicírculos se dá em função do ângulo de tomada estar ligeiramente deslocado para a direita e em contra-plongê (tomada de baixo para cima).

\section{Diagonais e Pontos Áureos}

Fica demostrado através destas linhas a simetria da composição como também a leve descentralização do ponto de luz - tanto no sentido vertical como horizontal devido ao ângulo de captação da imagem - contra-plongê e ligeiramente tendido para o lado direito, consequentemente alteração de perspectiva. Os pontos áureos delimitam quase a totalidade dos elementos, fica fora de seus limites apenas a parte superior da mão e uma pequena porção de um dos dedos.

Professor

Então oh além dessa coisa da produção colocando um plástico... oh...quando você vê a foto, qual é a ideia de estética de organização, o que você me diz disso?

Eli

Ah... não sei, na hora não pensei...Na hora queria conseguir alguma coisa.

Nos momentos anteriores ao demonstrar as apropriações que a aluna fez das regras de composição e como subordinou sua fotografia a essas normas técnicas. Embora ela seja taxativa ao dizer não ter pensado nessas questões na hora de fotografar, no turno dialógico acima, as fotografias deste sujeito denotam compreensão e apropriação dos conceitos.

Conhecer e justificar os motivos da aluna para tal afirmação demanda reflexão, pois como poderia subordinar os elementos de sua fotografia às regras formais vigentes 


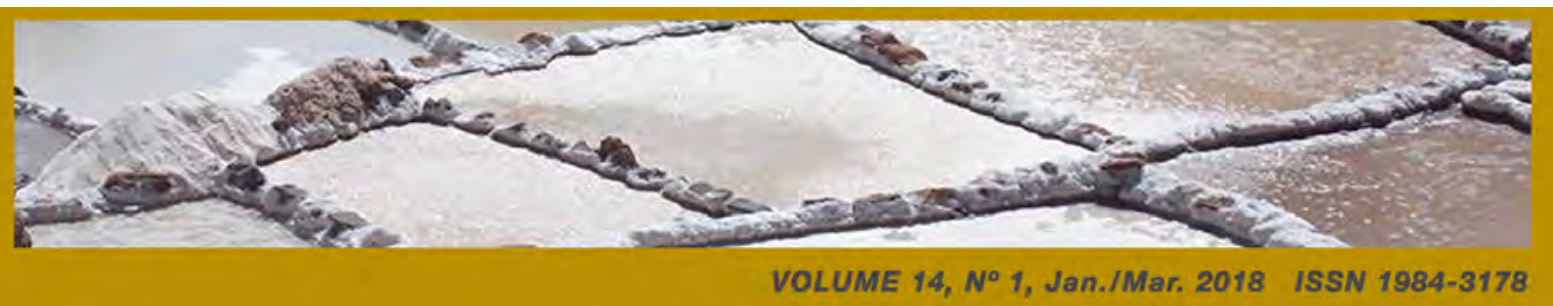

sem pensar sobre elas? Entendo sua dificuldade em verbalizar e, principalmente, em falar de conceitos complexos quando tudo que diz está sendo gravado.

No entanto, a elaboração das fotografias se deu em sucessivas etapas com várias produções individuais, cada uma delas foi corrigida e discutida com todos os sujeitos. Assim, durante as aulas e no decorrer da pesquisa, os conceitos técnicos compunham as discussões, ora relembrados pelo professor, ora pelos alunos. Portanto, houve decisões que se fundamentaram no que foi aprendido e discutido após várias fotografias produzidas.

Eli, ao afirmar não pensar sobre o que estava por fotografar, indicia que está em processo de apropriação de conhecimentos.

\section{RELAÇÃO}

Anteriormente evidenciei os aspectos formais e as maneiras como compreendi a maneira como a aluna se apropriou das regras de composição. Aqui, meu objetivo será analisar como se deram os processos de interação e como foram construídas as relações entre os sujeitos, os alunos, o professor e o pesquisador. Para tal, nossas conversas (ou poderia dizer "as aulas") estão carregadas de matizes diversos, pois estão presentes aulas vividas por mim, aulas que proferi e ainda projetos delineados para que utilizasse futuramente. Assim também levei em conta as possibilidades que a aluna teria em se utilizar de vários outros matizes para a construção de suas argumentações.

Agindo desta maneira favoreci que nossas vivências e nossas experiências concretas de vida fossem pensadas e (re)elaboradas diante de um processo interativo onde houve muito mais o acontecimento do que o um produto propriamente dito. Os sentidos passaram a se adequar aos significados que elaboramos juntos.

Compreender todo esse processo de interação e as manifestações materializadas nas fotografias ao qual estávamos expostos, significa debruçar-se sobre os desdobramentos contextuais, isto é, olhar atentamente a pormenores do como, do quando e do onde, como também, o dito e o não dito. Os silêncios, as entonações de 
voz, as expressões faciais, as brincadeiras demostram os vínculos construídos entre os sujeitos e são assim consideráveis por subsidiarem bases ao entendimento também ao professor/pesquisador.

A fotografia a ser discutida é da aluna Keila que falará em duas etapas, sendo a primeira delas ocorrida como as demais, isto é, seguiu-se a ordem de entrega da produção dos alunos. Já em sua segunda participação, foi convidada pelo professor, convite realizado para debater com a aluna Mercedes por esta ser mais próxima da aluna recém chegada à escola. Keila ainda não se enturmou. Quando expõe o que pensa em aula, mesmo não pretendendo, acaba provocando tensão consigo e seus colegas de sala.

Essa aluna é tida como muito esforçada por seus professores, chegou na escola no final do primeiro semestre, portanto, não participou dos estudos preliminares no ano anterior e dos iniciais do ano corrente. Compensou, solicitando no horário de intervalo a ajuda do professor. Essa atitude, em procurar o profesor, solicitando sua ajuda, é um processo análogo explicado por Vigotski (1983) ao afirmar que "a pessoa pode ir além do que iria sozinha se houver ajuda de outro".

Entendo a ação de Keila como uma busca por uma mediação que lhe permitisse realizar uma tarefa mais complexa, com a ajuda do professor sendo este o mediador que lhe apoiaria a realizar algo que os outros colegas já conseguem sozinhos.

Essa opção do professor é uma ação que visou o fortalecimento dos vínculos entre as alunas. 


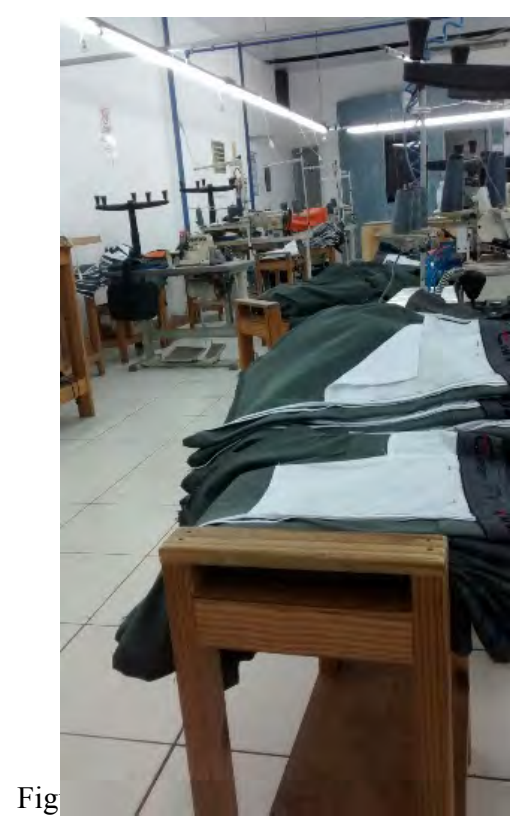

A fotografia que Keila produziu sintetiza sua preocupação com o mercado de trabalho, dado que a confecção, motivo da fotografia, é uma das primeiras indústrias de sua antiga cidade. Essas empresas possibilitaram a fixação dos jovens na cidade pois, anteriormente, elas eram obrigadas a procurar emprego em outros municípios.

Nas conversas com o professor, no horário de intervalo, disse que ao pensar sobre a situação dos jovens antes e depois da implantação das confecções, e agora, com as conversas sobre as fotografias "tudo passou a fazer mais sentido".

Professor

A Keila vai comentar sobre a foto dela. O interessante é que ela chegou no segundo semestre, então toda a parte de fotografia que vocês viram no ano passado, e no começo deste ano, ela não teve essa oportunidade.

Keila

Lá onde eu morava, o que mais tinha de serviço é fábrica de costura. Aí, eu achei importante pegar uma fábrica, porque aqui tem, até onde eu saiba (se referindo as confecções existentes em Arandu), mas não é tanto como lá ... (pausa) a maioria das pessoas trabalham com isso.

A aluna, ao comparar duas cidades diferentes sobre o mesmo aspecto e as relações que se estabelecem ao mercado de trabalho em ambas, faz eco nas palavras de Flusser (1983) quando nos ensina: 
Em lugar nenhum tem sido fácil a vida humana, porque tem sido, em toda parte e sempre, vida em cultura. Pois cultura é simultaneamente des-alienação e alienação, mediação e encobertura, emancipadora e condicionante. (FLUSSER, 1983, p. 137).

O elemento que ela destaca em sua fala, sua seleção do que é "importante" é a marca desse processo explicitado por Flusser em termos que trazem a marca da contradição. A escolha de Keila está marcada pelas escolhas do professor (quando estabeleceu o tema) e das imposições das economias locais. Ao esboçar a situação da cidade em que residia com a que está residindo estabelece que a relação do que une as cidades é a fábrica.

Keila

Para nós jovens não havia oportunidade, depois que você terminava a escola tinha que ir embora. As confecções não é lá uma coisa que se ganha bem, mas dá para sobreviver.

Keila

Com a chegada dessa fábrica a oferta subiu muito. Ajudou muito a cidade a crescer economicamente... eu acho... e dando mais oportunidade para ficar lá para trabalhar.

Professor Aqui em Arandu parece que a agricultura é bem forte.

Mercedes

Нит...Ниииит...

Professor

É esse o caminho que quer seguir?

Mercedes

Isso!

Professor

Gente, fala para mim... o tema era trabalho (refere-se ao tema das fotografias). Qual a importância do trabalho para vocês?

Mercedes

Trabalho é para tudo

Professor

E a Keila?

Keila

Eu acho que ele é importante. Porque é por ele que você tem uma base financeira...

Professor (afirma com meneio) 


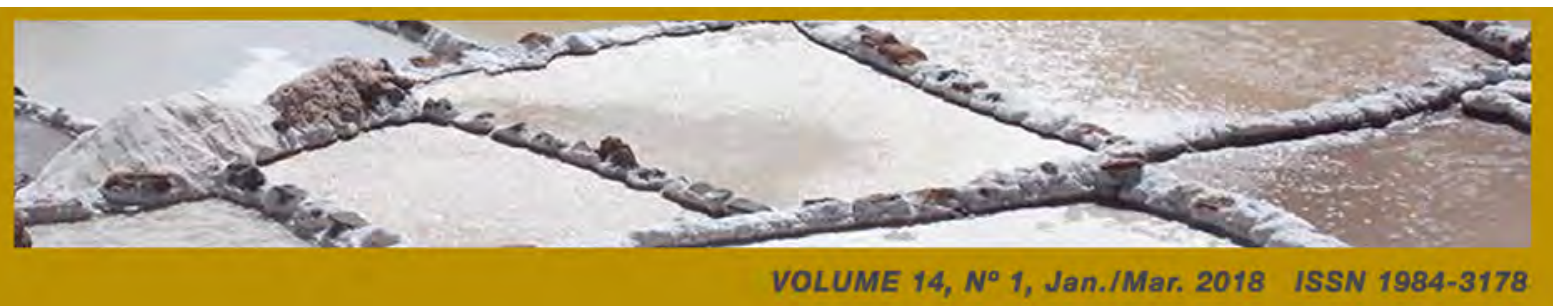

Keila

Para você hoje em dia conseguir algumas realizações na vida você precisa de dinheiro.

Professor

(afirma com meneio)

Keila

Tipo assim, no caso, tirando a parte de dormir, a parte do trabalho, ficar em casa com a família e também lazer.

Professor

Vocês acham que a gente trabalha demais?

Keila

Eu acho!

Mercedes

Нит...Ниииттт...

As falas do professor e as significações que criou acabaram sendo apropriadas pelas alunas e juntos passamos a (re) significar criando novos sentidos.

Os processos de significar e (re) significar tão evidentes nos turnos dialógicos acima, considerando que o grupo é pertencente a um segmento social, portanto, em uma relação compartilhada, podem ser explicados através das palavras de Flusser (1983) quando diz: "A sociedade vai sendo vivenciada e captada sempre mais claramente como aquela rede de relações devido à qual somos tout court.” (p.153).

Ou seja, criamos nossa consciência sobre nós mesmos através do outro, como também, damos a consciência de quem ele é. Uma outra passagem de Flusser (1983) nos dá uma visão ampliada de todo esse processo quando ele nos fala "Toda relação tem inúmeros aspectos, emocionais, culturais, econômicos, políticos, biológicos, éticos, jamais esgotáveis" (p.154).

\section{TRABALHO}

A última das discussões se refere a maneira de como os alunos significam o tema "Trabalho". Anteriormente foram mostradas as relações construídas entre os sujeitos e as maneiras que eles se apropriaram de significações veiculadas em aula de forma direta e indireta. 


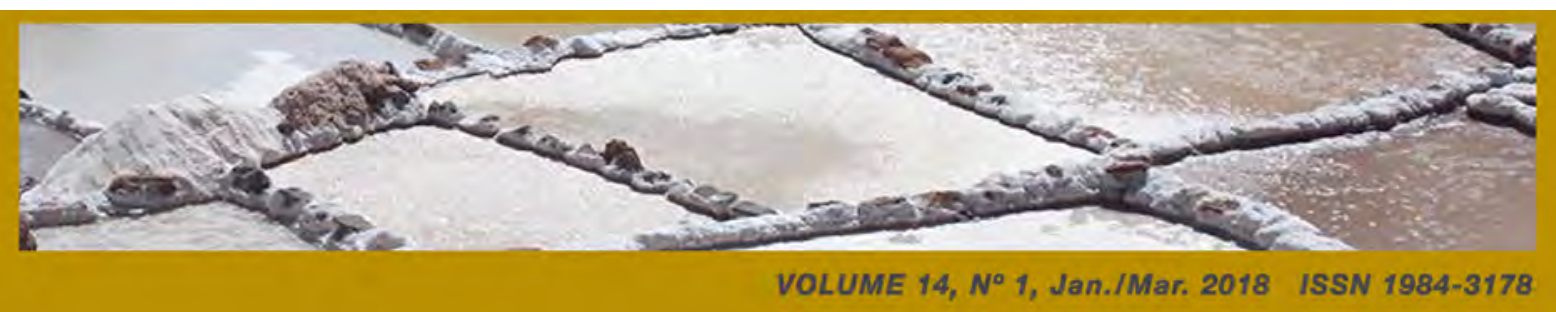

As conversas foram gestadas pela observação das fotografias que produziram, explicitando os modos como os alunos mediaram em suas fotografias os significados de trabalho. Conceitos apropriados do Currículo e do que foi coletivamente discutido, contrapostos, porém, pela forma de conceituar o tema pelo professor.

Neste sentido, a fotografia serviu como mote para as apropriações de significações construídas coletivamente. Desta forma, através dos diálogos, foi permitido ao professor/pesquisador analisar a internalização dos significados e a maneira como foi apropriada por seus alunos, ao produzirem suas fotografias.

Professor

Vamos ver de quem é a próxima... (Risos de todos).

Milena

Ai meu Deus... (ri muito) AH... AH...

Professor

É a do Fabiano.

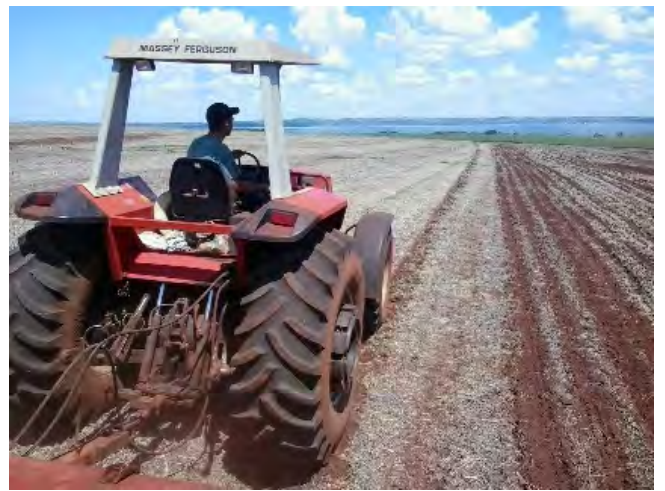

Figura 5 - Fotografia de Sujeito - Fabiano

Fabiano é bastante calmo, se relaciona muito bem com os colegas que normalmente o provocam, sempre responde a essas provocações de forma muito amistosa. Seu principal perfil é o de ser muito determinado e preocupado com a sobrevivência, segundo seus colegas e professores. 
Morador da zonal rural, sua família vive de duas rendas básicas conseguidas como caseiros de uma propriedade voltada ao lazer dos proprietários e como arrendatários meeiros de um sítio vizinho.

Neste sítio, produzem gêneros como hortifrútis vendidos à prefeitura local através de um programa do governo federal para melhoria da merenda escolar.

São suas tarefas, além da produção no campo, a entrega dos gêneros na cozinha piloto do município e, esporadicamente, também a entrega direta de frutas e hortaliças na escola. É destaque sua preocupação com a geração de renda e seu papel familiar na elaboração desta renda.

A fotografia e Fabiano é uma panorâmica de um campo de plantio sendo arado. Em primeiro plano está o trator e uma pequena parte do arado, ao fundo está a represa Jurumirim.

Elias

Essa ai é da fazenda...perto de casa (se referindo a fotografia do colega)

Milena (na intenção de descontrair o colega) É perto...?

Fabiano

É ... é perto! Daí tem a plantação (aponta para os detalhes da fotografia), tem a represa...

Ao apontar pontos específicos de sua fotografia, o aluno tem a intenção de estruturar a consciência através da imagem na qual a realidade é situação, assim demonstra a relação entre os elementos constitutivos da imagem e da realidade (FLUSSER,1983, p. 99).

Fabiano

Professor
Tem a represa, terra e o trabalho... melhor...

(na intenção de manter o foco no processo dialógico). Você colocou, assim ... coisas que eu acho importantes... você falou da represa, de 


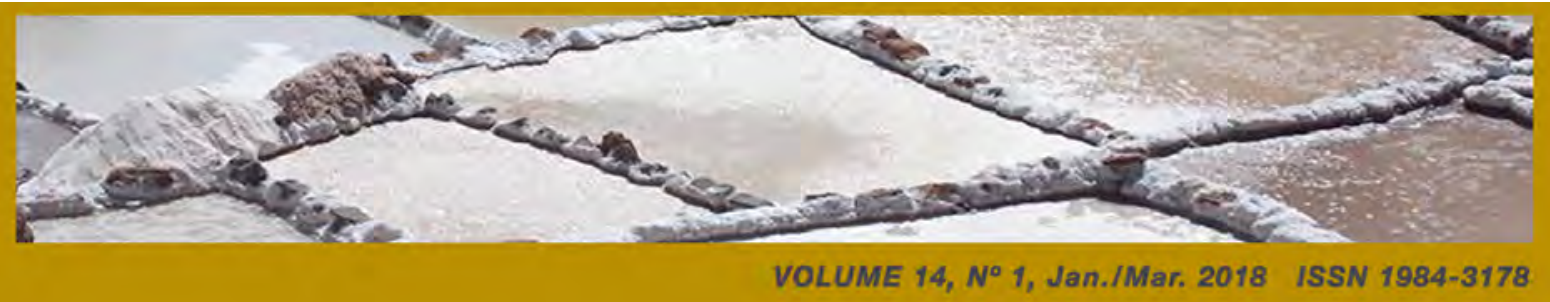

casa e de trabalho. Fala um pouquinho de cada uma dessas três coisas aí. De represa, casa e trabalho.

Fabiano

Professor

Fabiano

Professor

Fabiano

Professor

Fabiano

Professor

Fabiano
Do que representa para mim?

É, o que é para você, claro.

Ah... eu acho assim, que tem a beleza e o trabalho, né? A represa e o céu e a paisagem fazem parte da beleza. E o trabalho.

E o trabalho é importante para você?

$\dot{E} !$

Com quantos anos você está?

17

17! Então...oh, com 17 anos você está preocupado com o trabalho?

Isso, é que é uma fase que você tá também, sair da escola, o trabalho... é a mudança, né?

O aluno, ao assumir seu momento de mudança, assume sua adequação a uma programação, pois antecipadamente espera após concluir os estudos do Ensino Médio iniciar sua vida no mercado trabalho. Assim, adequa-se ao que foi programado (FLUSSER, 1983) pelo Currículo Escolar.

A sistematização do Currículo é configurada enfatizando ações que levem o aluno ao mercado de trabalho, a visão, ou melhor dizendo, a apropriação realizada por Fabiano. Assim, vê o trabalho de forma genérica, pois não encara o trabalho como manipulação de bens naturais de forma consciente pelo ser humano, como também não expressa que a produção de gêneros e mercadorias também levam a criação do empregado como mercadoria. 


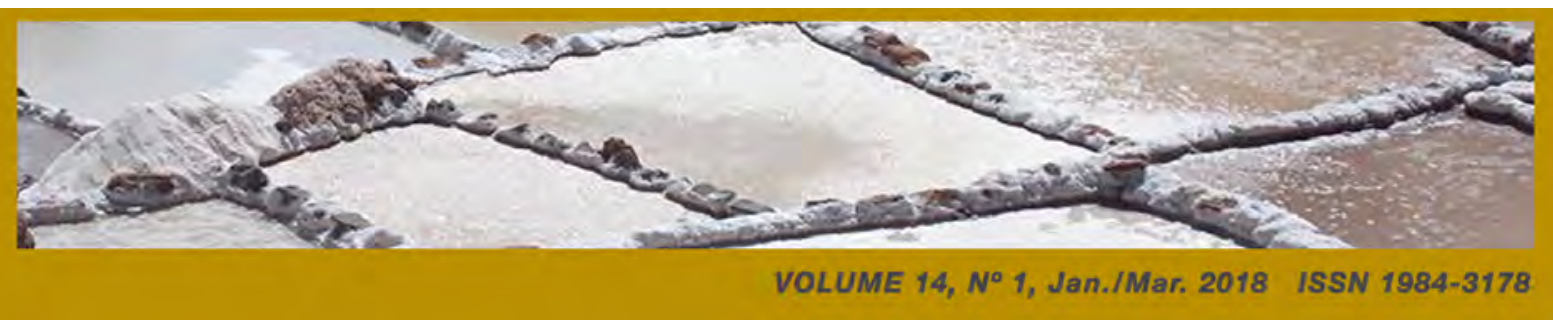

Fabiano

Mas como eu vivo nessa região e por enquanto eu estou nisso, então é importante.

Professor

E a sua família vive?

Fabiano

É. A gente trabalha na chácara (referindo-se a propriedade de lazer), mas é o sítio ... (inaudível).

Professor

Na pior das hipóteses, você vai pegar na enxada!

Fabiano

É! Já estou acostumado com isso, já trabalho com isso.

Professor

Beleza... Daqui a pouco a gente volta. Vamos ver o próximo. De quem $e ́ ?$

Milena

$E u$.

Professor

Da Milena

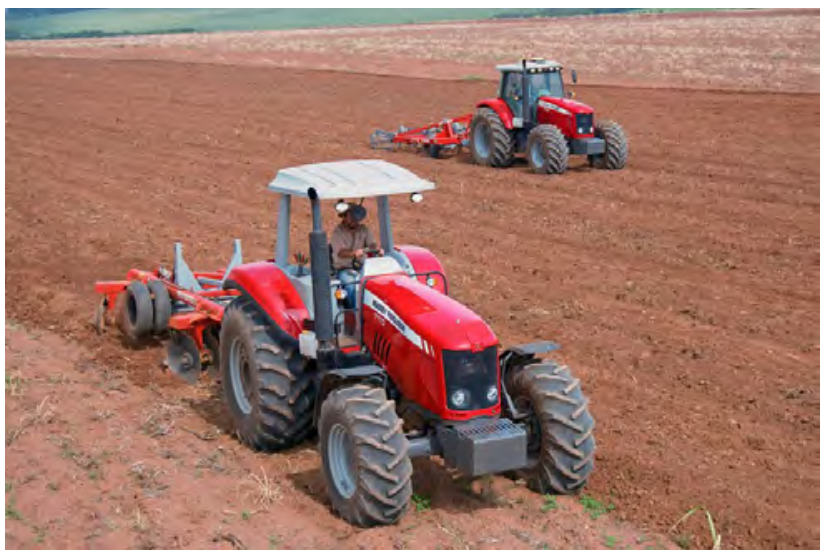

Figura 6 - Fotografia de Sujeito - Milena

Milena é uma menina extrovertida, fala espontaneamente, adorando provocar seus colegas com piadas e anedotas. É bastante disposta a dar sua colaboração, participando de todas as atividades da escola, não há evento que não participe. Foi estagiária da sala de informática da escola, na qual era elogiada por todos os usuários 
por sua determinação em colaborar. Realizava pesquisas junto com as pessoas, sugeria sites para, posteriormente, também ajudar na realização dos trabalhos.

Durante o ano em que estagiou, nos momentos em que não estava atendendo os usuários, fazia pesquisas sobre agricultura com destaque na produção de açúcar e álcool. Pouco a pouco foi refinando suas pesquisas e através de correio eletrônico entrou em contato com vários autores redimindo suas dúvidas. Discute com seus colegas de classe, explanando sobre detalhes da produção.

Milena

Professor

Milena

Professor

Milena

Professor

Milena
Esse eu fiz diferente, né! No outro (se refere a outra fotografia) eu tinha pegado (indecifrável), neste eu peguei a cana mesmo. Da minha área.

Você me contou, outro dia... quando eu perguntei em aula. Porque você se interessava tanto por essas coisas da terra, da agricultura, e você deu uma explicação. Mas eu não gravei. A gente já tinha falado de gravar. A gente já tinha parado de gravar naquele dia... ai eu falei (se referindo ao pensamento) vou cobrar isso da Milena de novo. A sua foto do ano passado foi de um trator. Não foi?

Do ano passado não!

E do que foi então?

O ano passado eu tirei da represa. Lá do Cristo em Vida (comunidade).

Verdade! Ai a primeira desse ano fez do trator, uma foto belíssima. E agora outra com trator. Fala pra mim daquela importância da terra para você. Como é que você descobriu isso?

Vem de bastante tempo, eu queria fazer agronomia, de entrar nessa área. Aí por influência do meu pai, eu tinha até desistido já. Aí o ano retrasado eu comecei a fazer açúcar e álcool... (pausa breve - referindose a um curso que realizou) en vi mesmo que en gostava e ele viu também que eu gostava... tá apoiando mais (referindo-se ao seu pai) agora. Por isso que eu fui visitar a plantação de cana, tudo certinho. 
Milena ao informar sua desistência num primeiro momento em cursar Agronomia, embora essa profissão, para a aluna seja um sonho confesso, é longínquo e impedido pelas condições financeiras de sua família. Por este motivo que seu pai a influencia a desistir, suas posses são limitantes.

Professor

Milena
Primeiro ele não apoiava (se referindo ao pai da aluna).

Não! Ele achava que era porque eu tinha exemplos de vizinhos de amigos. Ele acha que era por eu ver a vida deles que eu queria, não porque eu gostava. Depois que eu fiz o curso, que eu peguei o diploma, ai ele começou a ver que eu gostava... então agora ele apoia.

A aluna transparece que as profissões agrícolas são maioria em Arandu, dentre essas profissões a de agrônomo é a que traz maior conforto financeiro, bem como a que melhor dá status social. Justifica a própria aluna sobre a resistência de seu pai quando informa que ele achava que ela estava influenciada pelas posses dos vizinhos e amigos. Milena sustentou seu sonho ao fazer o curso técnico de produção de açúcar e álcool, adaptou assim seu sonho para uma condição mais próxima de sua realidade financeira. Com muito entusiasmo, todos os dias trazia para a escola os conhecimentos que adquiriu na noite anterior em seu curso técnico. Dava palpites na forma que seus colegas, principalmente Fabiano, trabalhavam no campo sugerindo sempre formas de melhorar os procedimentos.

Milena nasceu na cidade, os gostos e preferências profissionais foram criados através de seu convívio social. Sua opção em trabalhar como técnica agrícola é uma apropriação deste condicionamento social. Não poderia essa aluna negligenciar a maior fonte de emprego de sua região.

Professor

Milena

Professor
Então, você vai virar uma plantadora de cana!

Se Deus quiser!

Então você vai virar uma boia-quente, não uma boia-fria! 


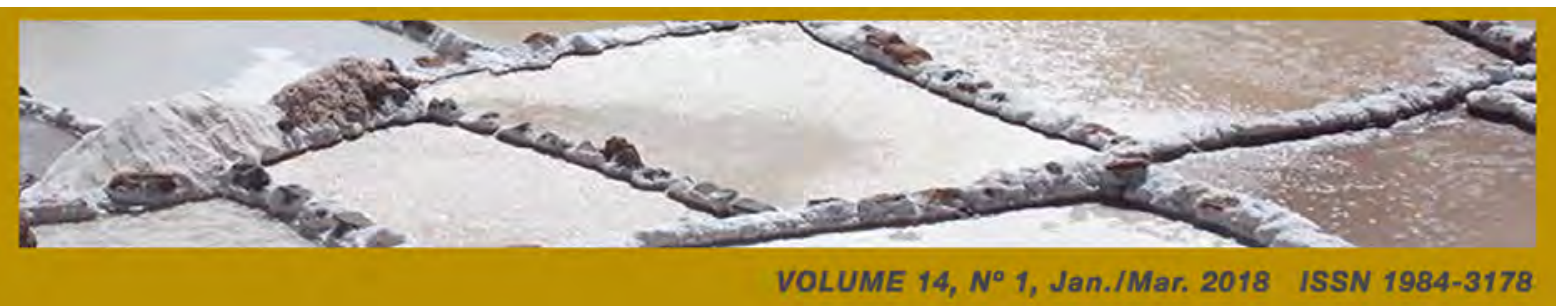

Milena

(rindo) Quente!

Discussões sobre a fotografia suscitam reflexões sobre a vida cotidiana, considerados os modos conotativo e denotativo fazendo emergir consciências, conforme nos ensina Flusser (2008) quando nos fala:

Tal consideração do input do output da caixa preta do aparelho permite localizar o nível ontológico no qual as consciências do imaginador e minha se assentam ao receber suas imagens. É ele o lugar onde o universo calculado e computado começa a emergir sob a forma de superfícies imaginárias e imaginadas. (FLUSSER, 2008, p. 55 - grifos meus)

A fotografia de Milena como também a de Fabiano fazem eco à preocupação com o mercado de trabalho. A aluna preocupou-se em representar sua área de atuação, isto é, retratou parte dos serviços de tombamento da terra para a plantação de cana de açúcar.

As opiniões apresentadas sobre a reflexão que pode a fotografia proporcionar remetem as palavras de Flusser (2008): “O importante é que as imagens técnicas são projeções que projetam significados de dentro para fora, e que é isso o seu "sentido"". (p. 65)

Os alunos embora necessariamente não tenham modificado sua concepção de trabalho tiveram a efetiva oportunidade de pensarem sobre ele, mediados pelas fotografias que produziram, (re)significando suas concepções iniciais. Assim, o professor agiu através de sua mediação para que o processo de (re)significar fossem possíveis.

\section{CONSIDERAÇÕES}

Inicialmente, em trechos anteriores, me distanciei de questões metodológicas demonstrando para o leitor minha constituição como pessoa e como profissional por acreditar que um estudo com essa envergadura não deva partir de um "nada" ou de 


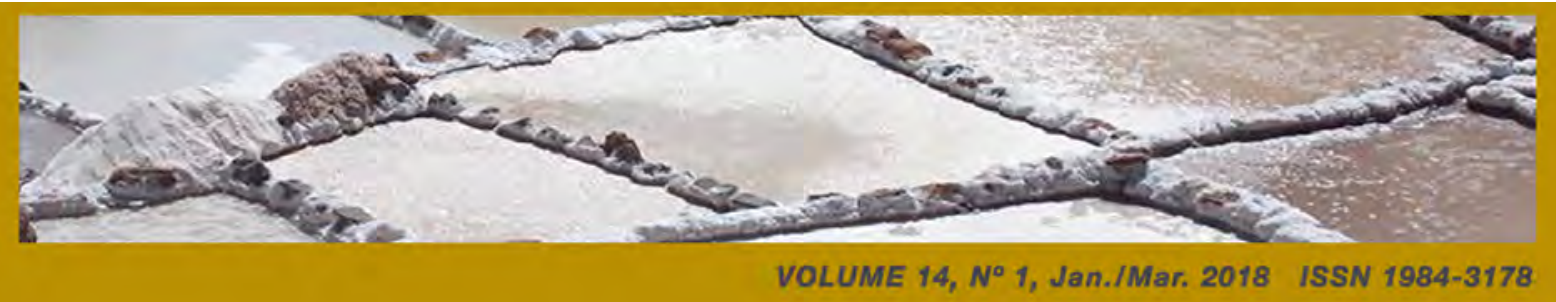

conceituações de outros. Assim, essa explicitação foi minha primeira postura metodológica.

Acreditei que ao explicitar ao leitor minha constituição e as apropriações realizadas durante a vida a partir de concepções criadas pelas vivências que tive, posicionaria mais profundamente aqueles que se interessam por questões como fotografia e educação, como também, despertaria o interesse, conforme o trabalho foi se desdobrando.

Depois, segui a trajetória a que me propus em busca de um rumo, trazendo minha forma particular de conceituar a fotografia e, posteriormente, os conceitos circulantes construídos através da pesquisa bibliográfica.

De posse de toda essa significação passei a mergulhar no trabalho com os alunos trazendo paralelamente suas fotografias e os diálogos realizados. No entanto, sempre que possível após trazer as vistas do leitor às fotografias trouxe um pequeno relato de quem seria o aluno, suas particularidades e suas apropriações do mundo concreto, para depois demonstrar as apropriações formais que cada um dos alunos selecionados realizou. Sendo essa minha segunda opção metodológica.

Cada uma das fotografias de meus alunos foi elaborada a partir de suas concepções de mundo e na forma que eles se relacionam com os conhecimentos socialmente adquiridos. No estudado durante todo o decorrer do segundo e terceiro ano do Ensino Médio, como também em todo o decorrer da pesquisa procurei subsidiar, tecnicamente, conhecimentos e reflexões sobre fotografia que garantissem as interpretações e construções coletivas sobre seu mundo real.

Balizado sobre as apropriações formais, onde também demonstrei as relações entre os sujeitos e como interagiram, foi visualizada como os desdobramentos aconteceram.

Assim, atribuindo significados às falas dos alunos, crio possibilidades para que (re)signifiquem seus pensamentos, possibilitando irem além e de forma mais elaborada do que antes fariam sozinhos. 


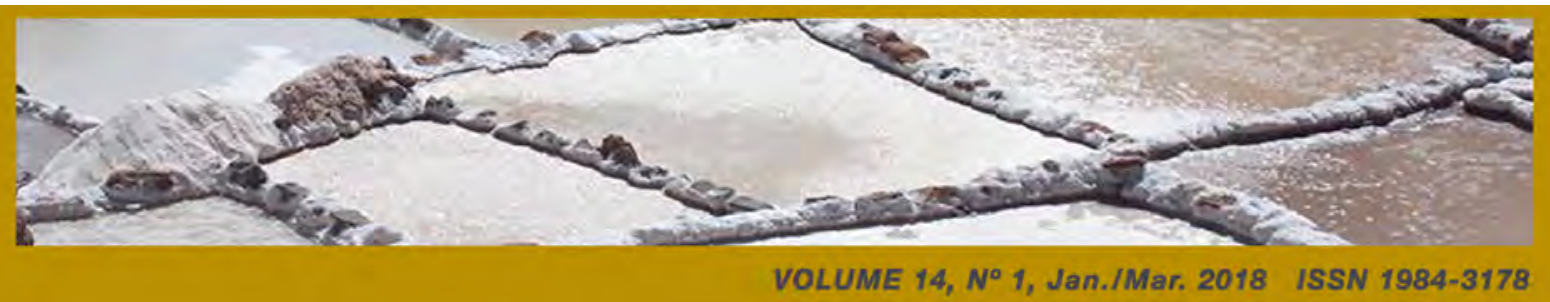

Por si só, os alunos não pensam sobre essas questões por estarem submetidos à ideias recorrentes, assim as intervenções possibilitam (re)significações, passando a pensarem de forma nova, ou melhor dizendo, possibilita a apropriação das questões como sendo elaboradas através de seu pensamento.

Por fim, foram demonstradas as maneiras como os alunos se apropriaram e como significaram o tema dado, isto é, o trabalho visto sobre a mediação do Currículo Oficial em contraposição às significações do professor/pesquisador.

\section{REFERÊNCIAS}

BUORO, Anamelia Bueno. O olhar em construção: uma experiência de ensino e aprendizagem da arte na escola. São Paulo: Cortez, 1998.

DELIBERADOR, Luzia Mitsue Yamasshita. et al. A Fotografia como Linguagem para a Formação Cidadã. Revista Discursos Fotográficos, 2013, Vol.9.

DUARTE, Elisabeth Bastos. Fotos \& Grafias. São Leopoldo: UNISSINOS, 2000.

FERREIRA, Anelise Barra. Aluno Faz foto? O Fotografar na Escola Especial. Tese de Doutorado em Educação. Universidade Federal do Rio Grande do Sul. 2012a .167p.

FERREIRA, Camila Otto Diniz. Fotografia como Crença: Construindo Narrativas, Ressignificando Memórias. Dissertação de Mestrado em Artes. Universidade Federal de Minas Gerais, 2012b. 160 p.

FLUSSER, Vilém. Pós-História: vinte instantâneos e um modo de usar. São Paulo: Duas Cidades, 1983.

AnnaBlume, 2008.

O Universo das Imagens Técnicas: Elogio da superficialidade. São Paulo:

GONÇALVES, Tatiana Fecchio da Cunha. Particularidades da Análise Fotográfica. Revista Discursos Fotográficos, 2009, Vol. 5.

KOSSOY, Boris. Realidades e Ficções na Trama Fotográfica. Cotia: Ateliê Editorial, 2002.

NOBRE, Itamar de Morais, GIGO, Vânia de Vasconcelos. Imagem Fotográfica, Cultura e Sociedade. Revista Discursos Fotográficos, publicação do Programa em Pós-Graduação da Universidade Estadual de Londrina, de periodicidade semestral, 2011, n 10, V. 7.

SONTAG, Susan. Sobre Fotografia. São Paulo: Cia das Letras, 2004. 


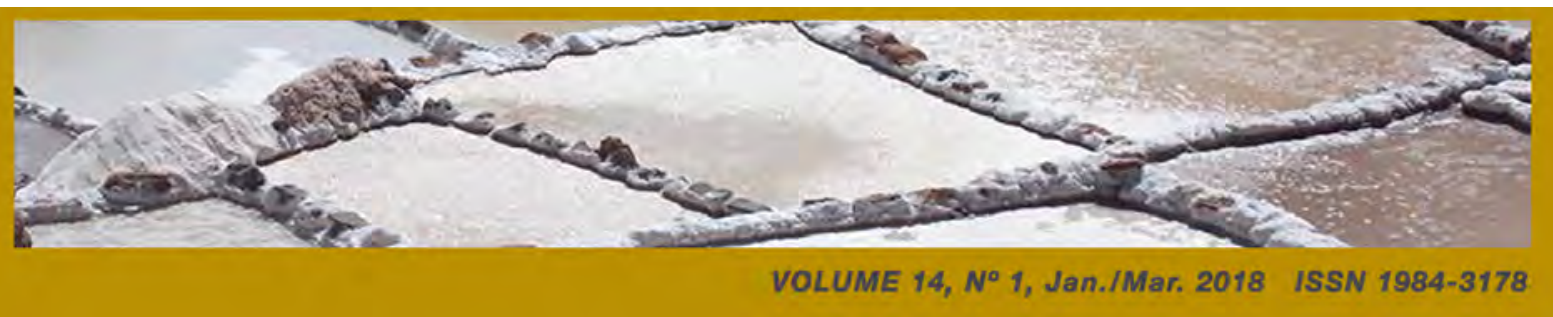

OSTROWER, Fayga. A Construção do Olhar. In NOVAES, A (et al). O Olhar. São Paulo: Cia das Letras, 1998.

ROUILLÉ, André. A fotografia: entre o documento e arte contemporânea. São Paulo: SENAC, 2009.

VIGOTSKI, Lev Semenovitch. Estúdio Del desarollo de las conceptos científicos en la idad infantil. In: Obras Escogidas II. Madri: Visor, 1983. p. 181-285.

Recebido em 31 de maio de 2017

Aprovado em 15 de novembro de 2017 